\title{
Unintended Compatability
}

National Cancer Institute

\section{Source}

National Cancer Institute. Unintended Compatability. NCI Thesaurus. Code C133636.

Problem associated with the ability of two or more devices which are intended to be incompatible but are able to work or fit together. 